\title{
Impact of Mikania micrantha H.B.K. Invasion on Diversity and Abundance of Plant Species of Chitwan National Park, Nepal
}

\author{
Binoj Kumar Shrestha ${ }^{1}$ and Dharma Raj Dangol ${ }^{2}$ \\ ${ }^{1}$ Institute for Social and Environmental Research-Nepal, Fulbari, Chitwan, Nepal \\ E-mail: binojstha@hotmail.com \\ ${ }^{2}$ Natural History Museum, Tribhuvan University, Swayambhu, Kathmandu, Nepal \\ E-mail-: dharmadangol@hotmail.com
}

\begin{abstract}
This research investigated the invasion of the alien plant Mikania micrantha H.B.K. and its impact on plant species richness and abundance in Chitwan National Park (CNP) forest. Stratified sampling technique was used to collect the information using the nested quadrats in the Mikania invaded and not invaded sites in July 2011. The study revealed that the invasion highly related with the vegetation structure of the habitat; higher the tree crown cover lower the invasion. On the other hand, the invasion in terms of cover percent of Mikania irrespective of the biomass (fresh weight) decreased plant species richness. Species richness showed unimodal response to the Mikania cover percent with the decrease after $35 \%$ of Mikania cover.
\end{abstract}

Keywords: Alien plant, species richness, biomass, unimodal response

\section{INTRODUCTION}

Invasion by non-native species represents one of the major threats to biodiversity (Tilman 1999, Davis 2003). The association between the global climate change and species invasion pattern suggests that the invasion rate by the alien species will not decrease soon (Cheung et al. 2009). The consequence of the augmenting invasion includes an array of ecological, economic and health impacts (Pimentel et al. 2005, Reaser et al. 2007, Groom et al. 2006). Even though Elton (1958) first raised the alarm of the impact of invasive species in the 1950s, the concern on the problem has increased only recently because of its serious impacts on global biodiversity (Tilman 1999, Sala et al. 2000, Davis 2003).

Mikania micrantha H.B.K. (hereafter called as Mikania) is also one of the worst invasive plants in the world (Lowe et al. 2000). Originating in Central and South America, its invasion has been reported throughout the tropical Asia including Nepal. It exhibits an exceptionally fast growth rate and a high sexual reproductive capacity (Choudhary 1972, Swamy \& Ramakrishnan 1987) and thus has earned the common name 'mile-a minute weed' (Holm et al. 1977). This perennial, sprawling vine damages or kills other plants by cutting out the sunlight and smothering them. It has been listed as one of the six worst invasive alien species that poses the highest risk to native ecosystems in Nepal (Tiwari et al. 2005).
When the Mikania first invaded in Nepal is not clear, however the first record of the Mikania could be found in the herbarium collected by Kitamura in 1963 (Tiwari et al. 2005). This plant has now invaded the forests, grasslands, wetlands, fallow lands and even in the croplands of tropical parts of Eastern to Central Nepal (Tiwari et al. 2005, Siwakoti 2007). The Chitwan National Park (CNP), a World Heritage Site is also found to be adversely affected by its invasion (Sapkota 2007, Shrestha et al. 2008). The extent of invasion and its impact on biodiversity is increasing each year and it is reported to be invaded that of about $20 \%$ area of the CNP (Khadka 2010).

The forest ecosystem in CNP is globally important for maintaining the invaluable biodiversity. This is one of the most important habitats for the remaining population of one horned rhinoceros and Bengal tiger and other important biological diversity. But it is so unfortunate that the problem of conservation is augmenting because of addition of the invasion by Mikania along with other factors. The problem is so drastic and increasing that even the immediate prime minister also observed the problem and initiated in the uprooting program in 2009. The forests and grasslands in CNP were free of Mikania micrantha in 2005 study, but the repeated study in 2007 recorded the invasion of Mikania (Shrestha et al. 2008). There are very little information on the ecology and impact of the 
invasive species in CNP. A detail study on Mikania was carried out in the invaded area of CNP (Sapkota 2007). However, to identify the more detail information on impact of invasion, a comparative study on invaded and non-invaded area is very crucial. On the other hand, the gradient of species diversity as well as abundance along the extent of invasion is required to assess the impact of invasion on native species. This study examined the impact of Mikania micrantha H.B.K. on diversity and abundance of plant species in CNP and identified factors responsible to inhibit the invasion success.

\section{MATERIALS AND METHODS}

\section{Study Area}

This study was conducted in the Chitwan National Park, particularly in the eastern sector called Sauraha, Chitwan (Fig. 1). The forest close to the rivers is the riverine forest type with Trewia nudiflora L. and Bombax ceiba L. as the dominant tree species. However, the vegetation of inner part of the park is dominated by Sal (Shorea robusta Gaertn.) forest and it covers the $70 \%$ of the park area. Sal is intermingled with chir pine (Pinus roxburghii Sarg.) along the southern face of the Churia Hills and with the trees Terminalia bellirica (Gaertn.) Roxb., Dalbergia latifolia Roxb., Anogeissus latifolius (Roxb. ex DC.) Wall. ex Guill. \& Perr., Dillenia indica L. and Garuga pinnata Roxb.on northern slopes. The riverine forest covers $10 \%$ of the park area and is dominated by Khair-Sissoo (Acacia catechu Willd.- Dalbergia sissoo Roxb. ex DC.) associations as well as Simal - Bhellar (Bombax ceiba - Trewia nudiflora). The remaining 20\% of the area is covered by the grasslands, where Themeda villosa (Poiret) A. Camus, Saccharum spontaneum L., and Imperata cylindrica (L.) Beauvois are the major plant species.

The Chitwan National Park is a home to 50 species of mammals, including the globally important species as one-horned Asian rhinoceros (Rhinoceros unicornis), tiger (Panthera tigris), Leopard (Panthera pardus), Wild elephant (Elephas maximus), etc (Bhuju et al. 2007). A larger number of birds (489 species), snakes (19 species including king cobra Ophiophagus hannah and Indian python Python molurus), crocodiles (2 species as mugger Crocodylus palustris and gharial Gavialis gangeticus) and 113 species of fish are also found due to the diversity in habitat (Bhuju et al. 2007).

The climate is subtropical with a summer monsoon from mid-June to late-September when $90 \%$ of the $2,400 \mathrm{~mm}$ of rain falls, and a relatively dry winter from October to February. The monsoon rains cause dramatic floods and alterations to the character and courses of rivers. Temperatures are highest during the monsoon period, with a maximum of $38^{\circ} \mathrm{C}$, and drop to a minimum of $6^{\circ} \mathrm{C}$ after the monsoon when dry northerly winds from the Himalaya and Tibetan Plateau are prevalent.
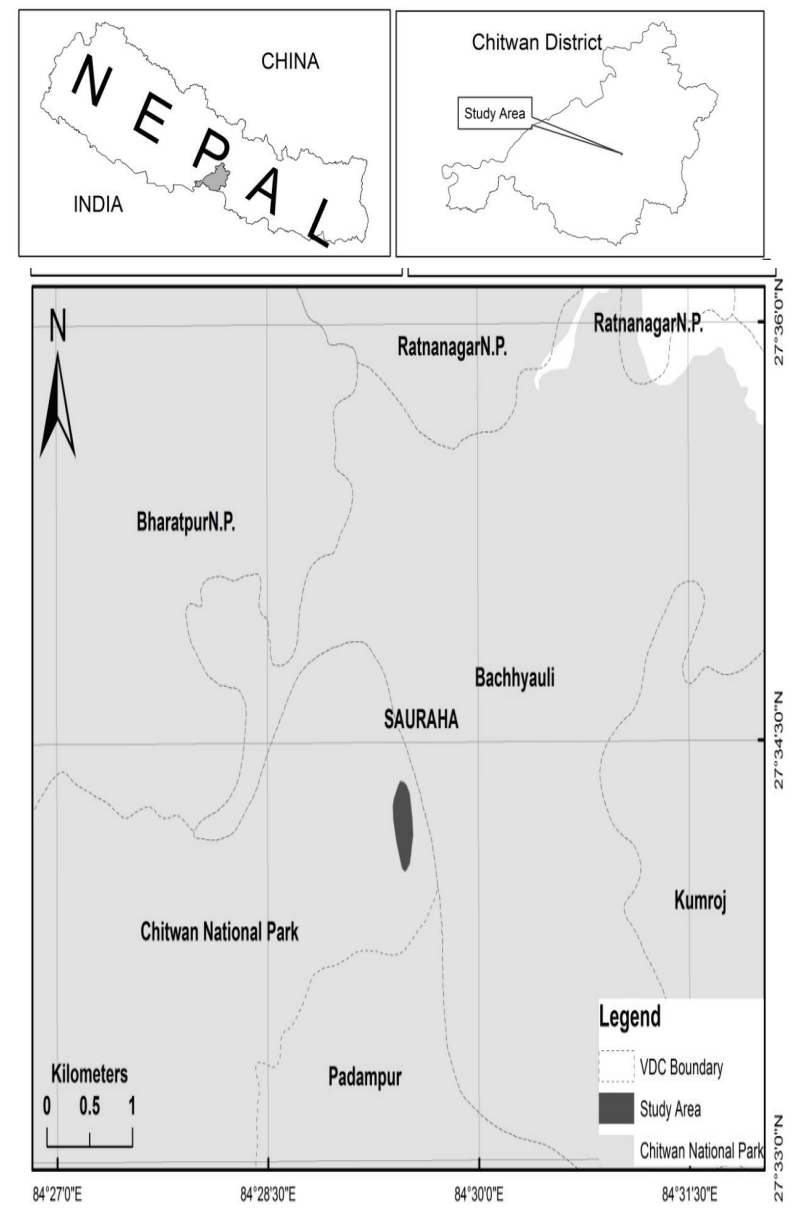

Fig. 1. Map of the study area

\section{Sampling}

The study was carried out by the standard systematic sampling methods making definite size quadrats in both invaded and not invaded areas. Based on the invasion pattern, 5 parallel transects were made starting from the edge of the forest towards the core region and hence covered the areas from invaded to invasion free areas. The distance of transects were maintained at 50 meters and similarly the plots in each transects were also established at a distance of 75 meters. The first plots in each transect was located at the edge of the forest and close to the river where as the last plots at the invasion free core area of the forest. The remaining two plots were made in between them at equal distance of 75 meters.

The size of the sampling plot was identified using the species area curve method. $10 \mathrm{~m} \times 10 \mathrm{~m}$ plots were used 
for the study of tree species and Mikania cover percent while $2 \mathrm{~m} \times 2 \mathrm{~m}$ plots in the mid of the larger plots were used to study the shrubs and saplings while three $1 \mathrm{~m} \mathrm{x}$ $1 \mathrm{~m}$ plots were held randomly inside the larger plots to study the Mikania biomass, herbs and seedlings.

\section{Data Analysis}

Within each sampling plots, GPS coordinates were recorded using GPS (GARMIN), name and population of plant species, cover percent by visual estimation and fresh weight of Mikania using the digital weighing machine. The univariate statistics was used to describe the data in the form of minimum value, maximum value, mean, and standard deviation for each variable. The bivariate relationship with Mikania cover and fresh weight and other vegetative characteristics have been analyzed using the Correlation Coefficient analysis. The impact of invasion (Mikania Biomass) on species richness and plant population (both total population and population of individual species) was analyzed by the Regression (Ordinary Least Square OLS) method. All the statistical analysis of Univariate, Bivariate and multivariate analysis has been performed using SPSS (IBM SPSS Statistics 19).

\section{RESULTS}

\section{Vegetation composition}

The first study area (the riverine forest) was dominated by the Trewia nudiflora L. tree species. Bombax ceiba L. and Dhatrung (Ehretia laevis Roxb.) were the associated species but had the very scarce distribution. The vegetative composition and their quantitative data are shown in the Table 1. On average, only 2 trees were recorded in a plot (100 square meters) while the crown covered about $49 \%$ areas of each plots on average. A total of 44 plant species were recorded, however the average total species richness in a plot was just 5.73 with the maximum records of 12 species in a plot. The species richness of the shrub and herbaceous layers were 3.84 and 3.15, respectively. Mikania micrantha H.B.K. invaded in such a way that it covered almost $45 \%$ of the research plots on average. The extent of invasion was also reflected by the cover percent of the plant that varied from 0\% (Mikania free) plots to the $90 \%$ in the highly invaded plots. While the biomass in terms of fresh weight was recorded as 395.36 grams per square meter, it also varied a lot among the plots with the standard deviation 426.44 .

The correlation analysis in between the different variables is shown in Table 2. The analysis shows that total species richness as well as shrubs and herbs species richness though negatively correlated with the biomass and cover percent of M. micrantha, the relationship is not significant. However, the correlation coefficient between the $M$. micrantha cover and tree population $(-0.62 * *)$ as well as $M$. micrantha and tree crown cover percent $(-0.74 * *)$ are strongly negative.

Table 1. Univariate statistics

\begin{tabular}{|l|c|c|c|c|}
\hline Variables & Min. & Max. & Mean & $\begin{array}{c}\text { Std. } \\
\text { Dev. }\end{array}$ \\
\hline $\begin{array}{l}\text { Biomass (grams) of } \\
\text { Mikania micrantha }\end{array}$ & 0 & 1386.66 & 395.36 & 426.44 \\
\hline $\begin{array}{l}\text { Mikania micrantha } \\
\text { cover (\%) }\end{array}$ & 0 & 90 & 43.68 & 32.99 \\
\hline $\begin{array}{l}\text { Total species } \\
\text { richness }\end{array}$ & 0 & 12 & 5.73 & 4.05 \\
\hline Tree population & 0 & 4 & 1.94 & 1.47 \\
\hline $\begin{array}{l}\text { Tree crown cover } \\
\text { (\%) }\end{array}$ & 0 & 90 & 48.42 & 32.78 \\
\hline $\begin{array}{l}\text { Shrub species } \\
\text { richness }\end{array}$ & 0 & 9 & 3.84 & 2.94 \\
\hline Shrub population & 0 & 144 & 50.31 & 47.19 \\
\hline $\begin{array}{l}\text { Herbaceous species } \\
\text { richness }\end{array}$ & 0 & 11 & 3.15 & 2.87 \\
\hline
\end{tabular}

Table 2. Pearson correlation coefficient among the variables

\begin{tabular}{|l|c|c|}
\hline \multirow{2}{*}{ Variables } & \multicolumn{2}{|c|}{ Mikania micrantha } \\
\cline { 2 - 3 } & Fresh weight & Cover \\
\hline Total species richness & -0.08 & -0.39 \\
\hline Tree population & -0.21 & $-0.62^{* *}$ \\
\hline Tree crown cover & -0.43 & $-0.74^{* *}$ \\
\hline Shrub sp. richness & -0.12 & -0.19 \\
\hline Shrub population & 0.16 & 0.07 \\
\hline Herb species richness & 0.02 & -0.29 \\
\hline
\end{tabular}

\section{Invasion dynamics}

Mikania was found to be affected by tree population, crown cover and the distance from the edge of the forest. The regression analysis showed the significant linear decrease of invader cover percent with the measured variables. As explained by the regression model, increase in one individual tree decreased the Mikania cover percent by about $15 \%$ while increase in tree cover by $1 \%$ decreased the invasion cover by $0.75 \%$. Similarly, when we move from the edge to the core parts of the forest the invasion gradually decreased and absent at certain distance. The result showed that as we move 1 meter inside the forest from the edge, Mikania cover percent decreases by half percent (Fig. 2). 

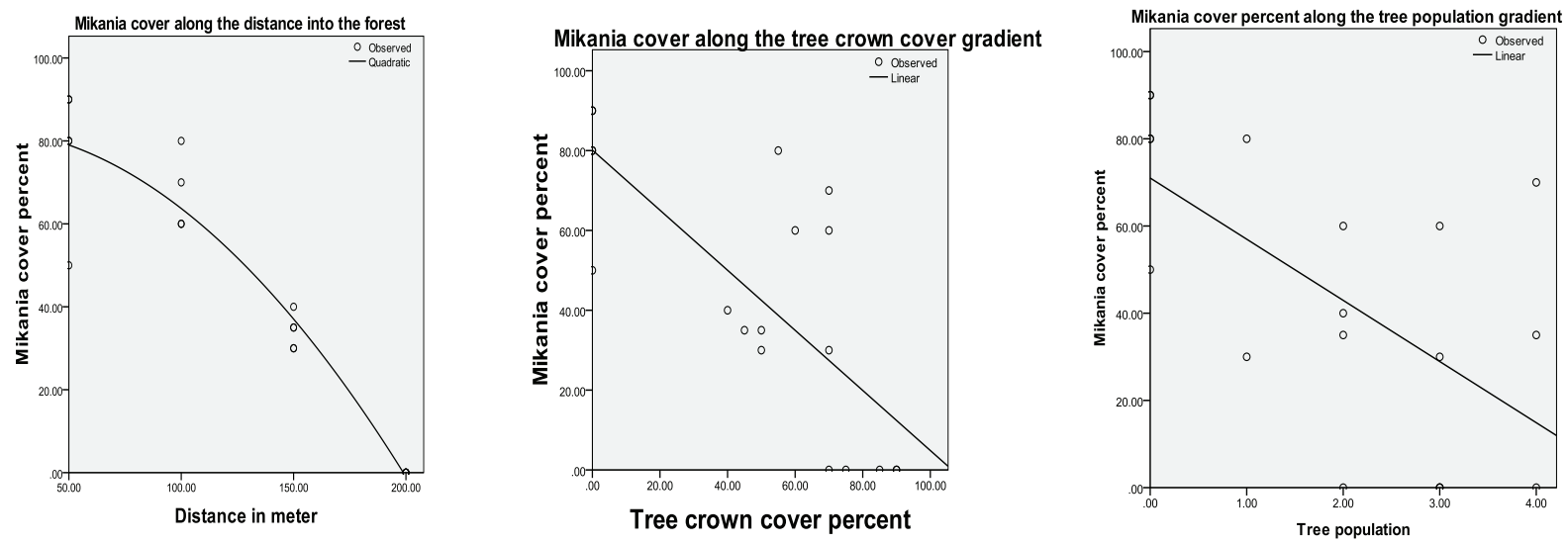

Fig. 2. Invasion dynamics along the environmental gradient

Table 3. Result of the Regression analysis with Mikania cover as dependent variable (Model $1=$ linear effect and Model 2 = unimodal effect)

\begin{tabular}{|l|c|c|c|c|}
\hline Predictors & Reg. Coeff. & Adjusted $\mathbf{R}^{2}$ & t -value & Sig. $(\boldsymbol{p})$ \\
\hline Tree population & & & & \\
\hline Model 1 $\left(\mathrm{F}=10.92, \mathrm{p}=0.004^{* *}\right)$ & -14.027 & 0.355 & -3.305 & $0.004^{* *}$ \\
\hline Model 2 $\mathrm{F}=7.79, \mathrm{p}=0.004)$ & 6.22 & 0.43 & 1.8 & 0.091 \\
\hline Tree crown cover & & & & \\
\hline Model 1 $\left(\mathrm{F}=21.58, \mathrm{p}=0.000^{* *}\right)$ & -0.753 & 0.534 & -4.646 & $0.000^{* *}$ \\
\hline Model 2 (F=11.32, $\mathrm{p}=0.001)$ & -0.007 & 0.534 & -1.014 & 0.326 \\
\hline Distance into the forest (Strata) & & & -11.74 & $0.000^{* *}$ \\
\hline Model 1 $\left(\mathrm{F}=137.85, \mathrm{p}=0.000^{* *}\right)$ & -0.531 & 0.884 & -2.523 & $0.023^{*}$ \\
\hline Model 2 $(\mathrm{F}=93.86, \mathrm{p}=0.001)$ & -0.002 & 0.912 & & \\
\hline
\end{tabular}

\section{Invasion and species richness}

The study of invasion dynamics showed that the invasion in terms of plant cover is inhibited by the tree crown cover but not by the tree population. But it is very interesting to find that shrub population has also the positive effect on the Mikania cover percent. As found in Model I, increase in shrub population by one individual increase the invasion by 0.38 percent. In Model II, when the disturbance gradient (where human interference with walking trails and river flooding is higher) was included the effect of tree characters faded away and showed significant negative impact on Mikania cover percent. As we move from the non-invaded plots to the edge of the forests, invasion increased by 31.68 percent in each stratum. When both the factors shrub population and disturbance gradient were fitted along with the tree characters, both of the variables showed accelerating effect on Mikania invasion.

Table 4. OLS regression estimates of the impact on Mikania cover percent

\begin{tabular}{|l|c|c|c|}
\hline Variables & Model I & Model II & Model III \\
\hline Shrub population & $0.388^{* *}$ & & $0.16^{*}$ \\
\hline Disturbance gradient & & $31.68^{* *}$ & $25.75^{* *}$ \\
\hline Control & & & \\
\hline Tree population & -7.389 & 0.895 & -2.42 \\
\hline Tree crown cover (\%) & $-0.712^{* *}$ & 0.181 & 0.02 \\
\hline
\end{tabular}

The ordinary least square (OLS) regression analysis shows the unimodal response of species richness with the invasion cover. The optimum number of species was recorded at about $35 \%$ of invasion and it decreased thereafter as shown in the figure. Almost no other species existed when the invasion cover is more than $90 \%$. But the multivariate analysis showed that species richness decreased significantly with the increase of invasion cover percent when the effect of tree population, crown cover and shrub population remain constant (Fig. 3). 


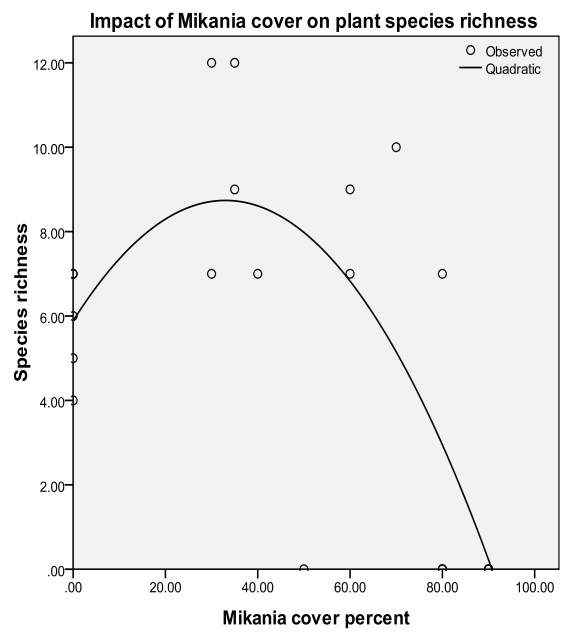

Fig. 3. Impact of Mikania cover on plant species richness

Table 5. OLS regression estimates of the impact of Mikania biomass and cover percent on species richness

\begin{tabular}{|l|c|c|c|}
\hline Variables & Model I & Model II & Model III \\
\hline Mikania biomass & -0.001 & & 0.001 \\
\hline Mikania cover (\%) & & $-0.047^{*}$ & $-0.057^{*}$ \\
\hline Control & & & \\
\hline Tree population & $1.274^{*}$ & 0.877 & 0.728 \\
\hline Tree crown cover (\%) & 0.006 & 0.022 & -0.019 \\
\hline Shrub population & $0.049^{* *}$ & $0.066^{* *}$ & $0.067^{* *}$ \\
\hline
\end{tabular}

\section{DISCUSSION}

\section{Vegetation Composition}

The first study areas was dominated by Bhellar (Trewia nudiflora $\mathrm{L}$.) tree species in major association with Simal (Bombax ceiba L.) and Dhatrung (Ehretia laevis Roxb.). Though the total number of species recorded in the study area was higher, the average total number of plant species per plot was just 5.73. It could be because of two reasons; first the study was carried out in plots. And smaller areas always show lower number of species compared to larger areas (Rosenzweig 1995). The second study area was very disturbed due to human as well as natural interferences (flooding) and higher disturbance degraded the habitat and made it unsuitable for many species and brought about the variation in species composition even in a small area. In addition the encroachment and increasing Mikania cover is the another reason for lower plant species diversity (Kaur et al. 2012). This is also supported by the correlation analysis between invasion and species richness. Though the output is not significant the negative sign of correlation reflects the relationship pattern between the variables. When the invasion extends and dominates an area, it alters the ecosystem structure and function (Vila et al. 2011). Then the species with lower or no resistive strength are excluded easily (Hejda et al. 2009). Here, the species mostly the herbaceous species could be considered as the resistive plants to invasion as they are surviving in the invaded areas.

\section{Invasion Dynamics}

Mostly, the alien species invade and dominates where the native vegetation is dwindled by either natural or human disturbances (Elton 1958, Primack 1995). Mikania invasion is also recorded to be higher along the forest edge towards the riverside and go on decreasing as move into the core areas. The cover percent up to $90 \%$ of the research plot along the forest edge shows the severe invasion problem in more disturbed area. Such severity is because invasive plants located near a vector pathway, such as road, trail or waterway; increase their chances of being dispersed by the vector using that pathway (Davies \& Sheley 2007). Proximity to waterways greatly increases the likelihood of water dispersal. For example, wind dispersal appendages, such as plumes and wings, would aid water dispersal by increasing buoyancy (Cousens \& Mortimer 1995).

In addition, such areas have lower plant population and provide the opportunity for invasion with lower competition for light and nutrients. As shown by the regression analysis, the invasion dynamics is significantly affected by both tree population as well as tree crown cover. Increase in tree population decreased the invasion cover percent by about $15 \%$. Disturbance in the form of resource use decreases either tree population or crown cover or both and that creates better condition for the invasion as well as rapid expansion of invasion. Higher tree population leaves narrow space for invasion and increase competition for the resources while higher crown cover reduces light availability which is also one of the inhibitor factors for the invasion. Hence, availability of space and light are the important factors for Mikania invasion and its growth. The linear negative effect of tree characteristics on invasion cover percent suggest that we have to maintain the optimum tree population as well as crown cover to protect the forest from the invasion vulnerability. Care should be given to protect the trees both from logging and lopping. As ecologically sustainable methods of control for invasive plants have not been invented yet, protection of the existing trees from logging and lopping could decrease further invasion while plantation of native tree species and its growth after certain years could bring a good results in invasion management and habitat restoration against the invasion problem. 


\section{Invasion and species richness}

The invasion of alien species is considered to be a great threat to native biodiversity (Tilman 1999, Davis 2003) due to its negative impacts. Many studies have already recorded that the alien invasion is harmful for the native species diversity (Kaur et al. 2012). This study also found similar results for the invasive plant Mikania micrantha H.B.K. This plant is known to have exceptionally fast growth rate and a high sexual and vegetative reproduction capacity (Choudhary 1972, Swamy \& Ramkrishnan 1987) and hence affects the native plants by limiting sunlight and nutrients. In addition, it retards the growth of other species due to the allelopathic effect (Ye \& Zhou 2001).

The bivariate analysis with Mikania cover and fresh weight with total species richness, shrub species richness and herbaceous species richness showed negative correlation. Though the result was not significant, it showed the direction of impact. It might be associated with other variables rather than Mikania invasion alone. But it is due to the unimodal response which was found from the regression analysis. Species richness increased from no invasion to $35 \%$ of invasion coverage and then decreased gradually as the plant cover increased. The native plants species have their competitive ability to resist up to $35 \%$ of the invasion, more than this cover percent is unsuitable and hence could not grow and survive there. Thus, the negative impact of invasion does not hold true up to $35 \%$ of Mikania invasion cover. But the problem is that we can't manage the invasion cover up to this level as the plant has very fast growth rate. This result thus has a very significant implication in park management as it reveals that decreasing the invasion extent to lower extent could maintain the plant diversity in spite of the invasion. Hence, absolute removal is the best way however park managers should not wait for time and resources for such programs rather start partial removal to maintain the diversity and habitat condition.

On the other hand, the multivariate analysis showed that invasion extension in the form of plant cover increases with the shrub population and distance closer to the forest edge. The regression model I and II taking shrub population and Distance separately showed positive impact to invasion, if we keep the tree characteristics as tree population and crown cover as constant. Similarly, combining both variables in a model (III) also showed independent impact on invasion increment. The effect of shrub cover could be the indirect effect of tree characteristics. Areas where tree population and crown cover is lower, obviously the shrub population becomes higher. When Mikania invaded such areas, it found a good environment for establishment and growth. Since the lower height of the shrubs, Mikania could find the better anchorage and opportunity to expand than on trees. In addition, distance closer to the edge is more disturbed because of natural (flooding) as well as anthropogenic factors (resource collection and tourism) which created the forest edge more suitable for invasion growth and expansion. So the result also accords the results of the previous studies which showed that the disturbed sites are not only prone to invasion but also have severe impact to native species diversity after invasion.

\section{ACKNOWLEDGEMENTS}

First of all, we would like to gratefully acknowledge Nepal Academy of Science and Technology for providing the research grant. We are much indebted to Dr. Dirgha Jibi Ghimire, Executive Director and Dr. Prem B. Bhandari, Senior Research Scientist of the Institute for Social and Environmental Research Nepal (ISER-N), Chitwan for their generous support for the study as well as review of the manuscript. We would also extend our sincere gratitude to Department of National Park and Wildlife Conservation, Kathmandu and Chitwan National Park Office for providing the permission to conduct this research in Chitwan National Park, Sauraha. Thanks go to Madan K. Suwal and staff of ISER-N for their direct and indirect help for this study.

\section{REFERENCES}

Bhuju, U.R., Shakya, P.R., Basnet, T.K. and Shrestha, S. 2007. Nepal biodiversity resource book: protected areas, Ramsar sites, and World Heritage sites. ICIMOD and MOEST/GON, Kathmandu.

Cheung, W.W.L., Lam, V.W.Y., Sarmiento, J.L., Kearney, K., Watson, R. and Pauly, D. 2009. Projecting global marine biodiversity impacts under climate change scenarios. Fish and Fisheries 10: 235-251.

Choudhary, A.K. 1972. Controversial Mikania (climber): A threat to the forests and agriculture. Indian Foresters 98: $178-186$.

Cousens, R. and Mortimer, M. 1995. Dynamics of weed populations. Cambrige University Press.

Davies, K.W. and Sheley, R.L. 2007. A conceptual framework for preventing the spatial dispersal of invasive plants. Weed Science 55: 178-184.

Davis, M.A. 2003. Biotic globalization: Does composition from introduced species threaten biodiversity? BioScience 53: 481-489.

Elton, C.S. 1958. The ecology of invasions by plants and animals. Metheun, London

Groom, M. J., Meffe, G.K. and Carroll, C.R. 2006. Principles of conservation biology. Third Edition. Sinauer Associates Inc., USA. 
Hejda, M., Pysek, P. and Jarosik, V. 2009. Impact of invasive plants on the species richness, diversity and composition of invaded communities. Journal of Ecology, 97: 393-403.

Holm, L. G., Plucknett, D. L., Pancho, J.V. and Herberger, J.P. 1977. The world's worst weeds: Distribution and biology. University Press of Hawaii. Honolulu.

Kaur, R., Malhotra, S. and Inderjit 2012. Effects of invasion of Mikania micrantha on germination of rice seedlings, plant richness, chemical properties and respiration of soil. Biology and Fertility of Soils 48(4): 1-8.

Khadka, N.S. 2010. The invader that is strangling an ecosystem. (http://news.bbc.co.uk/2/hi/science/ nature/8576646.stm)

Lowe, S., Browne, M., Boudjelas, M. and Poorter, M. 2000. 100 of the world's worst invasive alien species. Invasive Species Specialist Group (International Union for the Conservation of Nature), Auckland. www.issg.org/booklet.pdf.

Pimental, D., Zuniga, R. and Morrison, D. 2005. Update on the environmental and economic costs associated with alien invasive species in the United States. Ecological Economics 52: 273-288.

Primack, R.B. 1995. A primer of conservation biology. Sinauer Associates, Inc. Publishers, USA.

Reaser, J.K., Meyerson, L.A., Cronk, Q., Poorter, M.D., et al. 2007. Ecological and socioeconomic impacts of invasive alien species in island ecosystems. Environmental Conservation 34(2): 98-111.

Rosenzweig, M.L. 1995. Species diversity in space and time. Cambridge University Press.
Sala, O.E., Chapman, F.S. III, Armesto, J.J., Berlew, E., Bloomfield, J. et al. 2000. Global biodiversity scenerios for the year 2100. Science 287: 1770-1774.

Sapkota, L. 2007. Ecology and management issues of Mikania micrantha in Chitwan National Park, Nepal. Banko Janakari 17 (2): 27-39.

Shrestha, B.K., Ghimire, D.J. and Dangol, D. R. 2008. Lahare banmara (Mikania micrantha) ko atikraman badhdo Chunauti (in Nepali). Paryabaran 89: 26-30.

Siwakoti, M. 2007. Mikania weed: A challenge for conservationists. Our Nature 5: 70-74.

Swamy, P.S. and Ramakrishnan, P.S. 1987. Weed potential of Mikania micrantha H.B.K. and its control in fallows after shifting agriculture (jhum) in north-east India. Agric. Ecosyst. Environ. 18(3): 195-204.

Tilman, D. 1999. The ecological consequences of changes in biodiversity: A search for general principles. Ecology 80: 1455-1474.

Tiwari, S., Adhikari, B., Siwakoti, M. and Subedi, K. 2005. An inventory and assessment of invasive alien plant species of Nepal. IUCN Nepal, Kathmandu.

Vila, M., Espinar, J.L., Hejda, M., Hulme, P.E., Jaros, V., Maron, J. L., Pergl, J., Schaffner, U., Sun, Y. and Pys, P. 2011. Ecological impacts of invasive alien plants: A meta-analysis of their effects on species, communities and ecosystems. Ecology Letters 14: 702-708.

Ye, W.H. and Zhou, X. 2001. The plant killer- Mikania micrantha in South China. Aliens 13: 7. 